\title{
Electrochemical, spectroscopic and theoretical studies for acid corrosion of zinc using glycogen
}

\author{
Mikitha Pais ${ }^{1} \cdot$ Padmalatha Rao $^{1}$
}

Received: 30 May 2020 / Accepted: 13 October 2020 / Published online: 20 October 2020

(C) The Author(s) 2020

\begin{abstract}
The objective of the work is to introduce and establish anticorrosion capabilities of a novel biopolymer glycogen (GLY) against sulfamic acid $\left(\mathrm{NH}_{2} \mathrm{SO}_{3} \mathrm{H}\right)$ induced corrosion of zinc. The corrosion and inhibition studies were done by electrochemical techniques such as potentiodynamic polarization (PDP) measurements and electrochemical impedance spectroscopy technique (EIS). Conditions were optimized to get maximum inhibition efficiency by varying the concentration of the inhibitor in the temperature range of 303-323 K. Activation and thermodynamic parameters were evaluated and discussed in detail. Suitable adsorption isotherm was proposed to fit the experimental results. Scanning electron microscopy (SEM), energy dispersive X-ray (EDX) and atomic force microscopy (AFM) studies were performed before and after the addition of inhibitor. Adsorption of inhibitor was further confirmed by UV-Visible spectroscopy. Quantum chemical calculations were done to establish the correlation between the structure of the inhibitor and its inhibition efficiency. Energy of HOMO, LUMO, energy gap $\Delta E$, dipole moment $(\mu)$ Mullikan charges were calculated. Different theoretical factor descriptors like the hardness $(\eta)$, and softness $(\sigma)$ electronegativity $(\chi)$, global electrophilicity $(\omega)$, nucleophilicity $(\varepsilon)$ and fraction of electron transferred $(\Delta N)$ were calculated. Inhibition efficiency of glycogen increased with increase in its concentration and with temperature. Maximum efficiency of $72 \%$ could be achieved for the addition of $0.05 \mathrm{~g} \mathrm{~L}^{-1}$ of GLY at $323 \mathrm{~K}$. Results were fitted into Langmuir adsorption iostherm. The surface of the metal turned visibly smoother in the presence of GLY. In addition the EDX studies showed increase in carbon content which re-affirmed the adsorption of GLY on the metal surface. The density functional theory (DFT) based theoretical studies supported the experimental observations.
\end{abstract}

Keywords Glycogen · Corrosion inhibition · Electrochemical studies · surface morphology · Adsorption studies · Theoretical studies

\section{Introduction}

Zinc is considered to be one of the important nonferrous metal due to its wide range of industrial applications (Alsaleh and Khalil 2014). Zinc undergoes moderate to severe corrosion in the $\mathrm{pH}$ above 12 and below 6 . In between this $\mathrm{pH}$ range, corrosion rate is reported to be moderate (Mahida and Chaudhari 2012; Vashi and Desai 2012; Charitha and Rao

Electronic supplementary material The online version of this article (https://doi.org/10.1007/s11696-020-01391-z) contains supplementary material, which is available to authorized users.

Padmalatha Rao

padmalatha.rao@manipal.edu

1 Department of Chemistry, Manipal Institute of Technology, MAHE, Manipal 576104, Karnataka, India
2018). Various industrial processes such as pickling, descaling etc. will expose the metal to acidic environments. This leads to the material loss and the metal becomes unsuitable for industrial application. The aqueous solution of sulfamic acid is an outstanding choice for acid cleaning applications. Compared with other dilute mineral acids, which are used as traditional pickling agents, sulfamic acid does not give corrosive fumes. It being solid, easy to handle and store. It has the tendency to solubilize scales with its $-\mathrm{NH}_{2}$ and $-\mathrm{OH}$ functional groups forming soluble compounds with most industrial deposits. It is less corrosive when compared to other mineral acids (Morad 2008; Hermas and Morad 2008). Thus sulfamic acid is emerging as better and safe pickling candidate. To prevent metal dissolution, addition of inhibitors to corrosive is recommended (Karthik and Sundaravadivelu 2016; Karthikeyan 2016; Verma and Quraishi 2016; Peng and Song 2002). Most of the commercial inhibitors 
are toxic in nature; therefore, replacement by environmentally benign inhibitors is necessary (Abdel Hameed et al. 2014). Consequently, they will have adverse effects both on human health and on environment. In corrosion inhibition studies, carbohydrate polymers represent a set of chemically stable, biodegradable and ecofriendly macromolecules with unique inhibiting strengths and mechanistic approaches to metal surface and bulk protection. They are extracted from natural sources and are regarded as low cost, renewable and readily available alternatives with essential and active groups responsible for the corrosion inhibition (Raja et al. 2013). Following up the previous work by our group for using eco-friendly green inhibitors for corrosion control of various engineering materials (Charitha and Rao 2017a, b, 2018a, b) we herein introduce a novel biopolymer glycogen (GLY) for the corrosion control of zinc in acid medium.

Glycogen is a biopolymer which is a mobilized storage of glucose unit. It is a giant and highly branched polymer. As shown in the Fig. S1, the glucose units are bonded to each other by $\alpha-1,4$-glycosidic linkage but branches are created by $\alpha-1,6$-glycosidic linkage at every tenth residue. It has got many $-\mathrm{OH}$ groups, and hence it can adsorb easily on the metal surface by forming a barrier film between metal and corrosive. In this work an attempt is made to study inhibition efficiency of glycogen (GLY) for the corrosion of zinc in $0.25 \mathrm{M}$ sulfamic acid medium. Experimental studies are supported by theoretical calculations using DFT method.

\section{Materials and methodology}

\section{Preparation of test coupon and inhibitor solution}

99.8\% pure zinc was used with the composition: $0.009 \% \mathrm{Al}$, $0.004 \%$ of $\mathrm{Cr}, 0.11 \%$ of $\mathrm{Cu}, 0.017 \%$ of $\mathrm{Fe}, 0.026 \%$ of $\mathrm{Mg}$, $0.004 \%$ of $\mathrm{Ni}, 0.006 \%$ of $\mathrm{Pb}, 0.005 \%$ of $\mathrm{Sn}$ and $99.8 \%$ of zinc A cylindrical metal zinc rod with a surface area of $0.95 \mathrm{~cm}^{2}$ was sealed with resin material. Material abrasion was first done with different grades of emery papers (220-1500) and then with disc polisher using lavigated alumina. The metal rods were washed using distilled water, dried and stored in a desiccator to avoid moisture before being used for corrosion studies.

Sulfamic acid (Sigma-Aldrich) was 99\% pure. Fresh solution of $0.25 \mathrm{M} \mathrm{NH}_{2} \mathrm{SO}_{3} \mathrm{H}$ was prepared by dissolving calculated amount of the crystals in double distilled water. Inhibitor solution was prepared by dissolving required weight of glycogen (Sigma-Aldrich, Molecular weight 666.6 Da) in $0.25 \mathrm{M} \mathrm{NH}_{2} \mathrm{SO}_{3} \mathrm{H}$. The inhibitor concentration used was in the range of $0.01 \mathrm{gL}^{-1}$ to $0.05 \mathrm{gL}^{-1}$. The experiments were conducted at the temperature range of $303 \mathrm{~K}$ to $323 \mathrm{~K}$, in a thermostat calibrated up to $\pm 0.5{ }^{\circ} \mathrm{C}$ under unstirred condition.

\section{Electrochemical measurements}

The corrosion rate measurements were done by electrochemical methods like potentiodynamic polarization (PDP) method and electrochemical impedance spectroscopy (EIS) method. Corrosion studies of zinc were carried out using electrochemical work station (CH600 D-series US model with $\mathrm{CH}$ instrument with beta software). The electrochemical cell used was a conventional three-electrode compartment Pyrex glass vessel containing $100 \mathrm{~mL}$ of $0.25 \mathrm{M}$ $\mathrm{NH}_{2} \mathrm{SO}_{3} \mathrm{H}$. Zinc was used as working electrode. Potential measurements were done with respect to saturated calomel electrode as reference. Platinum electrode was used as auxiliary electrode. Potentiodynamic polarisation (PDP) studies and electrochemical impedance spectroscopy (EIS) studies were carried out by the method reported in literature (Prakashaiah et al. 2018). Potentiodynamic polarisation studies were carried out immediately after impedance measurement without further surface treatment. In all the cases, minimum of 4-5 trails were done and average of best three agreeing values was reported.

\section{Surface morphology, elemental composition and surface roughness studies.}

Surface studies were done by immersing the metal in $0.25 \mathrm{M}$ $\mathrm{NH}_{2} \mathrm{SO}_{3} \mathrm{H}$ for $2 \mathrm{~h}$ without and with the addition of the GLY $\left(0.05 \mathrm{gL}^{-1}\right)$. Surface morphology of zinc was carried out using analytical scanning electron microscope (SEM) (JEOL JSM-6380L) in the magnification of 500×. Elemental mapping was done using energy dispersive X-ray (EDX) analysis. Surface roughness was ascertained by atomic force microscopy (AFM) technique, using 1B342 innova model.

\section{Spectroscopic analysis}

\section{UV visible spectroscopy}

UV/Visible spectra was taken for GLY in $0.25 \mathrm{M} \mathrm{NH}_{2} \mathrm{SO}_{3} \mathrm{H}$ medium and GLY in $0.25 \mathrm{M} \mathrm{NH}_{2} \mathrm{SO}_{3} \mathrm{H}$ medium after immersing zinc coupon for $24 \mathrm{~h}$. (UV-Visible, double beam spectrophotometer-2201).

\section{Theoretical studies}

Maestro Material Science, Schrodinger software was used to perform the quantum chemical calculations. The complete geometrical optimisation for investigated inhibitor molecule GLY was done by density functional theory (DFT) method. Calculations were performed using the hybrid functional with the correlation functional (B3LYP) and 6-31G as the 
basis set. The energies of the highest occupied $\left(E_{\mathrm{HOMO}}\right)$ and the lowest unoccupied $\left(E_{\text {LUMO }}\right)$ molecular orbitals energy were calculated and discussed in detail. Different theoretical descriptors like the energy gap (DE), hardness $(\eta)$, and softness $(\sigma)$ electronegativity $(\chi)$, global electrophilicity $(\omega)$, nucleophilicity $(\varepsilon)$ fraction of electron transferred $(\Delta N)$ were calculated in accordance with relevant equations. The frontier molecular orbital (FMO) energies i.e., the energy of the highest occupied molecular orbital $\left(E_{\mathrm{HOMO}}\right)$ and the energy of the lowest unoccupied molecular orbital $\left(E_{\mathrm{LUMO}}\right)$ and Mullikan's charge population were evaluated (Singh et al. 2016; Verma et al. 2016; Ansari et al. 2016; Kumar et al. 2013; Abd El Wanees and Seda 2019).

\section{Results and discussion}

\section{Open circuit potential measurements}

Measuring the variation of the open circuit potential (OCP) with time for the working electrode is important in defining domains of corrosion and inhibition. The variation of the $\mathrm{OCP}$ as a function of time for zinc in $0.25 \mathrm{M} \mathrm{NH}_{2} \mathrm{SO}_{3} \mathrm{H}$ solution in the absence and presence of $0.05 \mathrm{gL}^{-1} \mathrm{GLY}$ at $313 \mathrm{~K}$ is shown in Fig. S2. The potential of zinc metal was shifted to more noble direction with the addition of GLY. The progressive positive shift of the steady state potential with addition of GLY shows the ability to inhibit the acid corrosion of zinc (Abdel-Gaber 2007).

\section{Potentiodynamic polarisation measurement}

The potentiodynamic polarisation curve for $0.25 \mathrm{M}$ $\mathrm{NH}_{2} \mathrm{SO}_{3} \mathrm{H}$ at $313 \mathrm{~K}$, in the presence of varying concentrations of glycogen (GLY) is shown in the Fig. 1. From the plots, the electrochemical parameters like corrosion current density $\left(i_{\text {corr }}\right)$, Tafel slops, corrosion potential $\left(E_{\text {corr }}\right)$ were obtained. The percentage inhibition efficiency was calculated using the Eq. (1). Results of potentiodynamic polarisation methods are tabulated in Table 1.

$I E(\%)=\frac{i_{\text {corr }-i_{\text {corr(inh) }}}}{i_{\text {corr }}} \times 100$,

where, $i_{\text {corr }}$ : corrosion current density $\left(\mathrm{mA} \mathrm{cm}^{-2}\right)$ in the absence of inhibitor. $i_{\text {corr(inh, }}$ : corrosion current density in presence of inhibitor.

Corrosion current density and corrosion rate decreased with the increase in the concentration of GLY, thereby increasing the inhibition efficiency. The adsorbed inhibitor molecule was responsible in forming a protective barrier at the electrode/electrolyte interface leading to the isolation

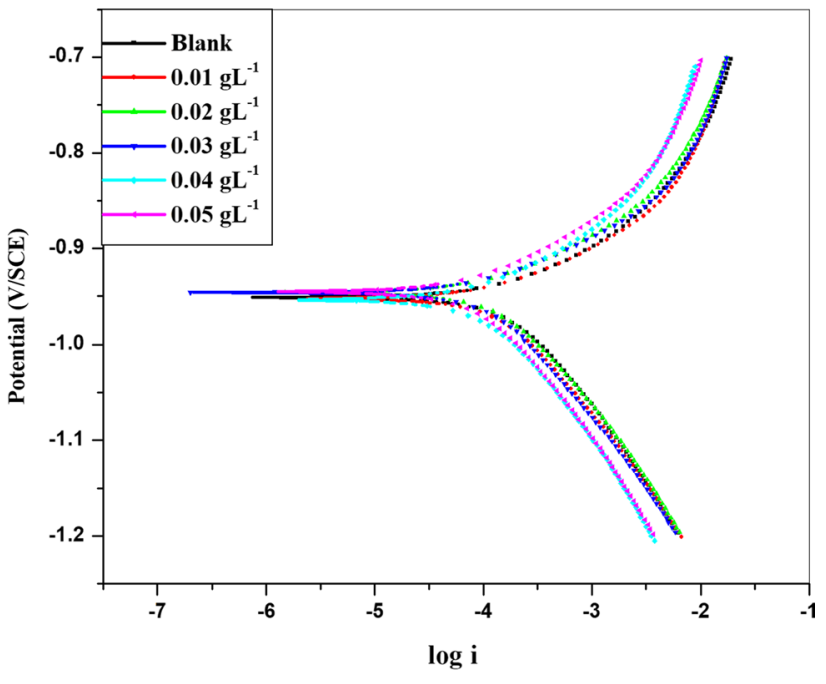

Fig. 1 Potentiodynamic polarisation plot for the corrosion control of zinc containing various concentrations of GLY in $0.25 \mathrm{M} \mathrm{NH}_{2} \mathrm{SO}_{3} \mathrm{H}$ at $313 \mathrm{~K}$

of metal from the corrosive environment thereby decreasing the corrosion rate (Bentiss et al. 2000).

In Fig. 1, anodic curve stands for dissolution of zinc while the hydrogen evolution is represented by the cathodic curve. There was no significant change in the shape of both the anodic and cathodic Tafel curves after the addition of inhibitor. After the addition of GLY, Tafel slopes remained almost the same as blank. This suggested that mechanism of both anodic and cathodic reactions remain almost unaffected after the addition of inhibitor. The inhibitor molecules adsorbed on the zinc surface and block the available reaction sites on the metal surface and brings down the corrosion rate without altering the mechanism (Khadiri et al. 2016; Abd El-Maksoud and Fouda 2005).

The standard electrode potential of zinc is $-760 \mathrm{mV}$. During corrosion and inhibition process, there was remarkable shift in corrosion potential. As per the reported literature, the shift can be due to two reasons. One possible reason is the passivity of the metal and another could be presence of oxidising agent in the corrosive. In the present study, observed shift was in the range of $-941 \mathrm{mV}$ to $-1001 \mathrm{mV}$ which could be attributed to the presence of free oxygen in the corrosive medium (Zhang 1996).

As per the reported literature ( $\mathrm{Li}$ et al. 2008), after the addition of inhibitor, if the shift in the corrosion potential $\left(E_{\text {corr }}\right)$ is more than $\pm 85 \mathrm{mV}$, the inhibitor can be distinctly considered as anodic or cathodic or else it can be regarded as mixed inhibitor. In the present study the observed difference is less than $+53 \mathrm{mV}$. It is slightly towards the positive side. It can be concluded that GLY acts as mixed inhibitor with more control on the metal dissolution. 
Table 1 Results of potentiodynamic polarisation measurements for the corrosion control of zinc containing various concentrations of GLY in $0.25 \mathrm{M} \mathrm{NH}_{2} \mathrm{SO}_{3} \mathrm{H}$

\begin{tabular}{|c|c|c|c|c|c|c|c|}
\hline Temp (K) & {$[\mathrm{GLY}]\left(\mathrm{gL}^{-1}\right)$} & $E_{\text {corr }}$ vs. SCE (mV) & $\begin{array}{l}i_{\text {corr }}\left(10^{-5} \mathrm{~A}\right. \\
\left.\mathrm{cm}^{-2}\right)\end{array}$ & $-\beta_{\mathrm{c}}\left(\mathrm{V} \mathrm{dec}{ }^{-1}\right)$ & $\beta_{\mathrm{a}}\left(\mathrm{V} \mathrm{dec}^{-1}\right)$ & CR (mpy) & IE $(\%)$ \\
\hline \multirow[t]{6}{*}{303} & Blank & -951 & 11.02 & 7.89 & 12.22 & 68.41 & - \\
\hline & 0.010 & -949 & 10.01 & 7.59 & 11.37 & 65.93 & 9.10 \\
\hline & 0.020 & -953 & 09.33 & 8.78 & 12.83 & 57.38 & 15.3 \\
\hline & 0.030 & -964 & 08.60 & 7.76 & 12.27 & 53.43 & 21.9 \\
\hline & 0.040 & -948 & 08.15 & 8.15 & 13.79 & 50.66 & 26.0 \\
\hline & 0.050 & -964 & 07.07 & 7.76 & 13.46 & 45.99 & 35.7 \\
\hline \multirow[t]{6}{*}{308} & Blank & -947 & 15.96 & 7.68 & 11.37 & 126.9 & - \\
\hline & 0.010 & -969 & 13.92 & 7.81 & 11.81 & 86.44 & 12.7 \\
\hline & 0.020 & -973 & 12.62 & 7.73 & 12.02 & 78.37 & 20.9 \\
\hline & 0.030 & -944 & 11.47 & 7.78 & 11.94 & 72.47 & 28.1 \\
\hline & 0.040 & -941 & 10.47 & 7.87 & 12.63 & 65.01 & 34.3 \\
\hline & 0.050 & -951 & 09.25 & 7.89 & 13.00 & 56.25 & 42.0 \\
\hline \multirow[t]{6}{*}{313} & Blank & -951 & 21.63 & 7.23 & 10.05 & 134.3 & - \\
\hline & 0.010 & -952 & 18.40 & 7.52 & 10.88 & 115.9 & 15.0 \\
\hline & 0.020 & -946 & 15.45 & 7.81 & 11.15 & 95.98 & 28.5 \\
\hline & 0.030 & -946 & 13.58 & 7.69 & 12.07 & 84.34 & 36.7 \\
\hline & 0.040 & -954 & 12.12 & 7.21 & 10.54 & 75.25 & 43.9 \\
\hline & 0.050 & -945 & 10.46 & 7.28 & 11.57 & 64.95 & 51.6 \\
\hline \multirow[t]{6}{*}{318} & Blank & -972 & 30.03 & 6.96 & 09.82 & 186.5 & - \\
\hline & 0.010 & -960 & 24.29 & 7.16 & 09.82 & 150.8 & 19.1 \\
\hline & 0.020 & -947 & 20.02 & 7.41 & 10.60 & 124.3 & 33.3 \\
\hline & 0.030 & -958 & 17.28 & 7.25 & 10.79 & 107.3 & 42.4 \\
\hline & 0.040 & -954 & 14.10 & 7.71 & 11.34 & 87.50 & 53.0 \\
\hline & 0.050 & -951 & 11.83 & 7.54 & 12.71 & 73.49 & 60.6 \\
\hline \multirow[t]{6}{*}{323} & Blank & -1001 & 40.53 & 6.85 & 08.91 & 251.7 & - \\
\hline & 0.010 & -944 & 31.02 & 6.36 & 09.34 & 190.3 & 23.4 \\
\hline & 0.020 & -960 & 24.29 & 7.16 & 09.82 & 150.8 & 40.0 \\
\hline & 0.030 & -948 & 19.83 & 7.54 & 10.77 & 120.4 & 51.0 \\
\hline & 0.040 & -953 & 16.43 & 7.63 & 10.86 & 102.0 & 59.4 \\
\hline & 0.050 & -953 & 11.65 & 7.83 & 12.83 & 72.33 & 71.2 \\
\hline
\end{tabular}

Inhibition efficiency of GLY increased with increase in temperature. This is suggestive of chemical adsorption of inhibitor onto the metal surface (Zulfareen et al. 2018). At $323 \mathrm{~K}$ a maximum efficiency of $71.2 \%$ was observed for the addition of $0.05 \mathrm{gL}^{-1}$ of inhibitor in $0.25 \mathrm{M}$ sulfamic acid.

\section{Electrochemical impedance spectroscopy (EIS) studies}

Nyquist plots at $313 \mathrm{~K}$ for the corrosion of zinc in $0.25 \mathrm{M}$ $\mathrm{NH}_{2} \mathrm{SO}_{3} \mathrm{H}$ in the absence and presence of various concentrations of GLY is shown in Fig. 2. Shape of the Nyquist plots agrees well with that reported in the literature for the corrosion of zinc in various other acid medium (Abd El Wanees and Seda 2019; Abdel-Gaber 2007; Fouda et al. 2018).
The Nyquist plots consisted of single semi-circles. Semicircles have a large capacitive loop at high frequency (HF) region. This high frequency capacitive loop is indicative of charge transfer resistance in the absence and presence of the inhibitor. The diameter of the semicircle increased with the increase in GLY concentration. This shows that the GLY molecules gets adsorbed onto the surface of zinc and hinder the charge transfer process thereby decreasing the corrosion rate. A small tail preceding the capacitive loop reflects the solution resistance $\left(R_{\mathrm{s}}\right)$.

Figure 3 represents the impedance spectra for Nyquist plots by fitting the experimental data to the equivalent circuit model, using ZSimpWin software 3.1. The equivalent circuit consisted of the solution resistance $\left(R_{\mathrm{s}}\right)$, charge transfer resistance $\left(R_{\mathrm{ct}}\right)$ and time constant phase element $(Q)$. Solution resistance $\left(R_{\mathrm{s}}\right)$ is due to the combined resistance offered 


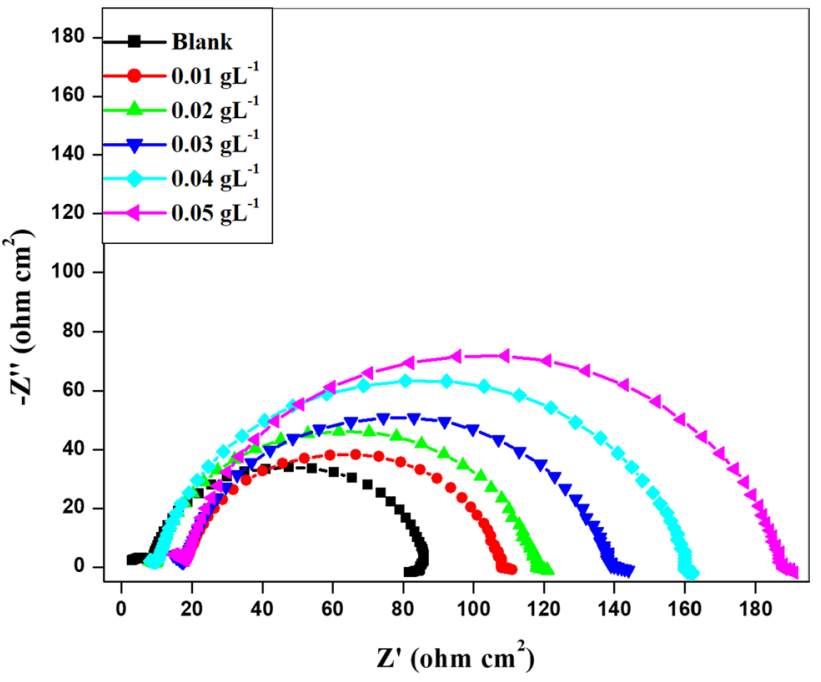

Fig. 2 Nyquist plot for the corrosion control of Zinc in the absence and presence of various concentrations of GLY in $0.25 \mathrm{M} \mathrm{NH}_{2} \mathrm{SO}_{3} \mathrm{H}$ at $313 \mathrm{~K}$

by the solution and the electrical connections. A pure double layer capacitor is replaced with a constant phase element to account for the depressed capacitive nature of Nyquist plot and the real capacitance can be calculated using Eq. (2) (Martinez and Metikoš-Huković 2003).

$C_{\mathrm{dl}}=Q\left(\omega_{\max }\right)^{n-1}$,

where $Q$ is the $\mathrm{CPE}, \omega_{\max }$ is the frequency at maximum impedance (imaginary part- $Z^{\prime \prime}$ ) and $n$ is the CPE exponent. If the value of $n$ is 1 , then CPE behaves like a capacitor. The average $n$ value was found to be around 0.87 . The small variation in the capacitance from its real value was calculated using Eq. (3) (Machnikova et al. 2008).

$$
C_{\mathrm{dl}}=\frac{1}{2 \pi f_{\max } R_{\mathrm{p}}}
$$

$f_{\max }$ is the frequency at which the imaginary component of impedance is maximum.

Equation (4) was used to calculate the polarization resistance $\left(R_{\mathrm{P}}\right)$ from the values obtained from circuit fitment.

$R_{\mathrm{P}}=R_{\mathrm{s}}+R_{\mathrm{ct}}$.

The values of electrochemical impedance parameters obtained from fitting the experimental data to the used equivalent model are presented in Table 2.

Polarisation resistance $\left(R_{\mathrm{p}}\right)$ increased and capacitance of electrical double layer $\left(C_{\mathrm{dl}}\right)$ decreased with the increase in GLY concentration. Added inhibitor molecules successfully replace water molecules near the interfaces. The adsorption of inhibitor molecules forms a physical barrier between the metal and corrosive, thereby increasing the polarisation resistance $\left(R_{\mathrm{P}}\right)$. The decrease in the dielectric constant and increase in the thickness of the double layer at metal/ electrolyte interface led to the decrease in the capacitance of electrical double layer $\left(C_{\mathrm{dl}}\right)$ (Khaled 2008). The inhibition efficiency obtained from the PDP measurements were in good agreement with that obtained from the EIS studies.

Bode plot explains the behaviour of electrochemical system depending upon the frequency. Fig. S3 represents the Bode plot for zinc in the absence and presence of various concentration of GLY. In the Bode magnitude plot, only a single slope was observed for both the blank and inhibited solution. In the Bode plot, the difference between the HF limit and LF limit corresponds to the $R_{\mathrm{p}}$ values and the difference increased with the increase in inhibitor concentration. (a)

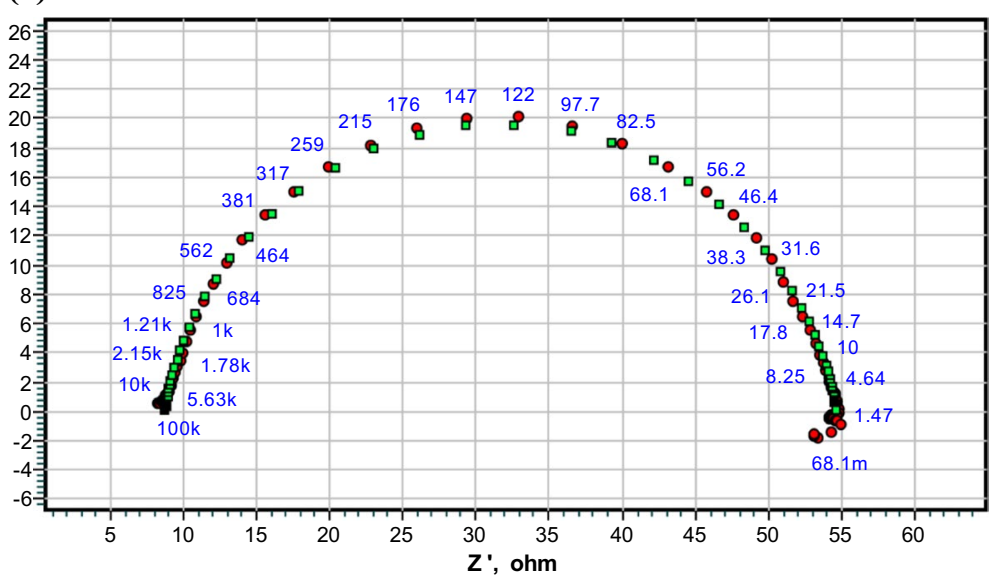

(b)

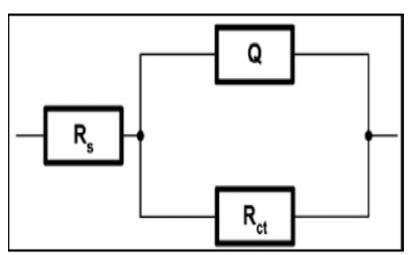

Fig. 3 a Stimulated circuit fitted to the obtained EIS data for $0.25 \mathrm{M} \mathrm{NH}_{2} \mathrm{SO}_{3} \mathrm{H}$. b Circuit used to fit the experimental EIS data 
Table 2 Results of EIS measurements for the corrosion control of zinc containing various concentrations of GLY in $0.25 \mathrm{M} \mathrm{NH}_{2} \mathrm{SO}_{3} \mathrm{H}$

\begin{tabular}{|c|c|c|c|c|c|c|c|c|c|}
\hline Temp (K) & {$[\mathrm{GLY}]\left(\mathrm{gL}^{-1}\right)$} & $R_{\mathrm{s}}\left(\Omega \mathrm{cm}^{2}\right)$ & $R_{\mathrm{ct}}\left(\Omega \mathrm{cm}^{2}\right)$ & CPE & $n$ & $\chi^{2}\left(\times 10^{-3}\right)$ & $R_{\mathrm{P}}\left(\Omega \mathrm{cm}^{2}\right)$ & $C_{\mathrm{dl}}\left(\mu \mathrm{F} \mathrm{cm}^{-2}\right)$ & IE $(\%)$ \\
\hline \multirow[t]{6}{*}{303} & Blank & 7.90 & 140.9 & 5.254 & 0.8561 & 3.36 & 148.8 & 18.53 & - \\
\hline & 0.01 & 16.9 & 151.9 & 4.305 & 0.8628 & 4.34 & 168.8 & 17.40 & 08.5 \\
\hline & 0.02 & 17.1 & 157.1 & 4.711 & 0.8623 & 4.61 & 174.2 & 14.68 & 14.5 \\
\hline & 0.03 & 17.3 & 167.8 & 2.480 & 0.8773 & 3.61 & 185.1 & 12.98 & 19.6 \\
\hline & 0.04 & 17.9 & 191.6 & 3.234 & 0.8886 & 4.93 & 209.5 & 08.77 & 28.9 \\
\hline & 0.05 & 10.1 & 225.2 & 1.633 & 0.8564 & 5.99 & 235.3 & 06.99 & 36.7 \\
\hline \multirow[t]{6}{*}{308} & Blank & 8.81 & 100.9 & 5.198 & 0.8865 & 9.02 & 109.7 & 30.42 & - \\
\hline & 0.01 & 10.9 & 113.4 & 4.490 & 0.8721 & 7.30 & 124.3 & 28.00 & 11.7 \\
\hline & 0.02 & 9.23 & 129.3 & 3.959 & 0.8917 & 2.95 & 138.5 & 21.88 & 20.8 \\
\hline & 0.03 & 9.29 & 144.3 & 3.850 & 0.8812 & 5.49 & 153.5 & 17.19 & 28.5 \\
\hline & 0.04 & 9.57 & 155.9 & 3.824 & 0.8720 & 4.90 & 165.4 & 16.65 & 33.7 \\
\hline & 0.05 & 16.4 & 178.1 & 3.421 & 0.8748 & 6.09 & 194.5 & 11.29 & 43.5 \\
\hline \multirow[t]{6}{*}{313} & Blank & 7.31 & 77.09 & 6.348 & 0.8482 & 3.62 & 84.41 & 55.86 & - \\
\hline & 0.01 & 10.2 & 92.55 & 4.014 & 0.8980 & 4.46 & 102.8 & 36.80 & 17.7 \\
\hline & 0.02 & 8.94 & 109.6 & 4.359 & 0.8978 & 2.25 & 118.5 & 30.26 & 28.7 \\
\hline & 0.03 & 11.4 & 118.8 & 5.515 & 0.8682 & 4.46 & 130.2 & 26.70 & 35.1 \\
\hline & 0.04 & 17.7 & 130.2 & 3.809 & 0.8785 & 3.02 & 147.9 & 20.98 & 42.9 \\
\hline & 0.05 & 3.64 & 179.8 & 4.305 & 0.8628 & 4.34 & 183.4 & 12.65 & 53.9 \\
\hline \multirow[t]{6}{*}{318} & Blank & 8.02 & 51.78 & 7.026 & 0.8277 & 2.22 & 59.88 & 114.8 & - \\
\hline & 0.01 & 8.52 & 66.90 & 3.445 & 0.9121 & 1.73 & 75.42 & 65.88 & 20.6 \\
\hline & 0.02 & 11.6 & 80.00 & 5.098 & 0.8874 & 5.47 & 91.61 & 42.64 & 34.6 \\
\hline & 0.03 & 8.54 & 100.2 & 3.796 & 0.8920 & 1.55 & 108.7 & 38.93 & 44.9 \\
\hline & 0.04 & 10.2 & 115.1 & 5.237 & 0.8650 & 8.31 & 125.3 & 28.10 & 52.2 \\
\hline & 0.05 & 9.81 & 133.0 & 3.377 & 0.8764 & 5.80 & 142.8 & 20.56 & 58.0 \\
\hline \multirow[t]{6}{*}{323} & Blank & 7.03 & 31.35 & 7.491 & 0.8526 & 1.21 & 38.38 & 292.5 & - \\
\hline & 0.01 & 8.70 & 40.46 & 5.540 & 0.8340 & 1.61 & 49.16 & 196.0 & 21.9 \\
\hline & 0.02 & 7.95 & 56.11 & 5.102 & 0.9198 & 2.54 & 64.06 & 96.68 & 40.0 \\
\hline & 0.03 & 8.33 & 67.60 & 5.399 & 0.9040 & 1.39 & 75.93 & 71.90 & 49.4 \\
\hline & 0.04 & 8.73 & 83.68 & 4.225 & 0.9003 & 1.64 & 92.41 & 48.40 & 58.4 \\
\hline & 0.05 & 11.2 & 119.1 & 5.604 & 0.8692 & 7.65 & 130.3 & 27.03 & 70.5 \\
\hline
\end{tabular}

\section{Effect of temperature}

Inhibition activity of GLY on zinc $0.25 \mathrm{M} \mathrm{NH}_{2} \mathrm{SO}_{3} \mathrm{H}$ was studied in the temperature range of 303-323 K. The inhibition efficiency increased with the increase in inhibitor concentration and also with the increase in the temperature. With increase in temperature, corrosion rate increases. With increase in corrosion rate number of active sites available for adsorption of inhibitor becomes more. Due to this more and more inhibitors get adsorbed thereby increasing the inhibition efficiency. Further, calculations of thermodynamic parameters clearly demonstrated the chemical adsorption of the inhibitor. This is an indication of endothermic reaction, where inhibition efficiency increases with temperature. Various kinetic parameters like energy of activation $\left(E_{\mathrm{a}}\right)$, Enthalpy of activation $\left(\Delta H_{\mathrm{a}}\right)$ and entropy $\left(\Delta S_{\mathrm{a}}\right)$ were calculated using Arrhenius law equation (Fig. S4a) and transition state equation (Fig. S4b).
Activation parameters for the corrosion of zinc in $0.25 \mathrm{M} \mathrm{NH}_{2} \mathrm{SO}_{3} \mathrm{H}$ containing different concentrations of GLY are tabulated in Table S1. Energy of activation (Ea) of the inhibited solutions was lesser than the uninhibited solution. The adsorbed GLY molecule blocks the process of charge transfer because of the presence of oxygen which can form coordinate bond with the zinc surface during the corrosion process (Zulfareen et al. 2018; Oguzie et al. 2008; Bouklah et al. 2006). Magnitude of enthalpy of activation $\left(\Delta H_{\mathrm{a}}\right)$ is almost matches with energy of activation. This further supports the endothermic process of zinc dissolution (Sahin et al. 2002) before and after the addition of inhibitor. The decreased value of entropy of activation $\left(\Delta S_{\text {ads }}\right)$ with increasing inhibitor concentrations reveals that a decrease in disordering takes place on going from reactant to the activated complex (Nwosu and Muzakir 2016). 


\section{Adsorption considerations}

Adsorption isotherms are constructed to validate the adsorption of inhibitor on to the surface. It is usual practice to try with various adsorption models like Freundlich, Langmuir, Temkin etc. Average correlation coefficient $\left(R^{2}\right)$ close to unity is considered as best fit. Experimental data of corrosion of zinc in $0.25 \mathrm{M} \mathrm{NH}_{2} \mathrm{SO}_{3} \mathrm{H}$ with GLY gave a perfect linear plot and best fitted into Langmuir adsorption isotherm, which is the plot of $C / \theta$ versus C (Fig. S5). Langmuir adsorption isotherm assumes that a solid surface contains a fixed number of adsorption sites and each site holds one adsorbed species (El-Deeb et al. 2018). Calculated values of the equilibrium adsorption constant $(K)$, slope and $R^{2}$ values for adsorption of GLY based on Langmuir adsorption isotherm are tabulated in Table $\mathrm{S} 2$.

From the intercept of adsorption isotherms, adsorption equilibrium constant $(K)$ was obtained, which is related to standard free energy of adsorption $\left(\Delta G^{\circ}\right)$ by Eq. (5)

$\Delta G_{\text {ads }}^{\circ}=R T \ln K$,

$K$ can be calculated as dimensionless the by Eq. (6) (Okafor and Zheng 2009)

$\Delta G_{\mathrm{ads}}^{\circ}=-R T \ln (1000 K)$.

The standard enthalpy $\left(\Delta H^{\circ}\right)$ of adsorption and standard entropy of adsorption $\left(\Delta S^{\circ}\right)$ were calculated using Gibbs Helmholtz equation, which is a plot of $\Delta G^{\circ}$ versus $T$ (Fig. S6) calculated thermodynamic parameters are tabulated in Table S2.

Generally, values of standard free energy of adsorption $\left(\Delta G_{\text {ads }}^{\circ}\right.$ ) up to $-20 \mathrm{~kJ} \mathrm{~mol}^{-1}$ are consistent with physisorption and those around $-40 \mathrm{~kJ} \mathrm{~mol}^{-1}$ or higher are associated with chemisorption as a result of sharing or transfer of electrons from the inhibitor molecule to the metal surface to form a coordinate bond. Negative values $\Delta G_{\text {ads }}^{\circ}$ suggested the spontaneity of the adsorption of GLY on metal surface
(Bentiss et al. 2001; Hosseini et al. 2003). $\Delta G_{\text {ads }}^{\circ}$ values were ranging in between $-23.18 \mathrm{~kJ}$ and $\mathrm{mol}^{-1}-27.47 \mathrm{~kJ} \mathrm{~mol}^{-1}$, which indicated the possibility of both physical and chemical adsorption. According to reported literature (El-Sherbini et al. 2005; Okafor and Zheng 2009; Quraishi et al. 2000; Krishnaveni et al. 2015) negative value of standard enthalpy of adsorption $\left(\Delta H_{\mathrm{ads}}^{\circ}\right)$, indicates the possibility of either physical or chemical adsorption. But positive value of $\Delta H_{\text {ads, }}^{\circ}$ univocally supports chemical adsorption. As reflected in the Table S2, standard enthalpy of adsorption is $41 \mathrm{~kJ} \mathrm{~mol}^{-1}$ for the current study. This clearly confirms the chemical adsorption of GLY onto the surface. $\Delta S_{\text {ads }}^{\circ}$ positive values reflect the increase in the solvent entropy as disorder occurs at the metal/solution interface. This is attributed to the displacement of $\mathrm{H}_{2} \mathrm{O}$ molecules by GLY molecules from the metal surface (Hu et al. 2015).

\section{Surface morphology studies}

\section{Scanning electron microscopy (SEM) analysis}

Careful observation of Fig. 4 reveals that, surface smoothness is maximum for Fig. 4c. Surface of zinc which became rough due to acid corrosion Fig. $4 \mathrm{~b}$ became very smooth due to the adsorption of inhibitor onto the metal surface. The added GLY was able to cover almost all the cavities present on the surface forming a barrier between the metal and the medium preventing further corrosion.

\section{EDX analysis}

The data of the elemental analysis are given in Table S3. The backbone of GLY is made up of carbon units. It is clear from the table that the addition of $0.05 \mathrm{gL}^{-1}$ GLY increased the $\%$ composition of carbon of the inhibited metal surface confirming the adsorption of GLY onto the metal surface and decreasing the extent of corrosion.
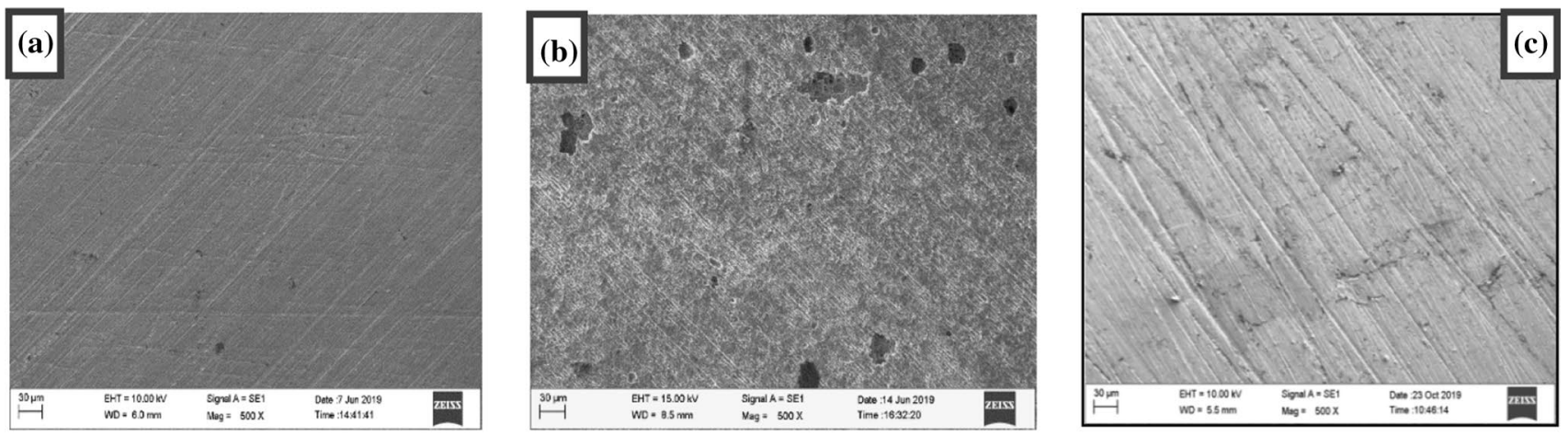

Fig. 4 a Freshly polished zinc metal (b) zinc metal +0.25 $\mathrm{M} \mathrm{NH}_{2} \mathrm{SO}_{3} \mathrm{H}(\mathbf{c})$ zinc metal $+0.25 \mathrm{M} \mathrm{NH}_{2} \mathrm{SO}_{3} \mathrm{H}+0.05 \mathrm{gL}^{-1} \mathrm{GLY}$ 


\section{AFM analysis}

Results of AFM analysis is given in Fig. 5a-c, and tabulated in Table S4. The average surface roughness $\left(R_{\mathrm{a}}\right)$, root mean square roughness $\left(R_{\mathrm{q}}\right)$ and $R_{\max }$ values dipped in acid in the absence of the inhibitor is higher than the inhibited sample. After the addition of GLY the extent of surface roughness is reduced this suggests that the GLY was able to bring down the corrosion rate by forming a physical barrier (Mishra et al. 2018; Verma et al. 2017).

\section{Spectroscopic analysis}

\section{UV visible spectroscopy}

UV-Visible absorption spectra obtained from $0.25 \mathrm{M}$ $\mathrm{NH}_{2} \mathrm{SO}_{3} \mathrm{H}$ solution containing $0.05 \mathrm{gL}^{-1} \mathrm{GLY}$ before and after the immersion of zinc coupon are shown in Fig. 6. The spectra confirmed the possibility of the formation of an GLY-Zn complex. The electronic absorption spectra of GLY before immersion of zinc coupon have an absorption maximum at $210 \mathrm{~nm}$, which can be attributed to $n-\sigma^{*}$ transition. Zinc coupons were immersed in the test solution for $24 \mathrm{~h}$,

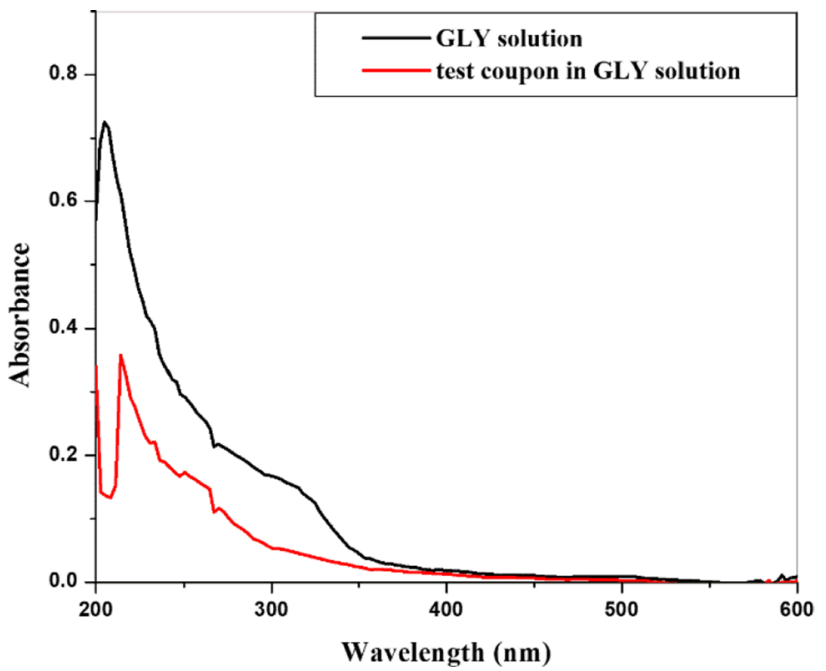

Fig. $6 \mathrm{UV}$-visible spectra of the solution from $0.25 \mathrm{M} \mathrm{NH}_{2} \mathrm{SO}_{3} \mathrm{H}$ containing $0.05 \mathrm{gL}^{-1}$ GLY before and after the immersion of zinc

the change in the position of the absorption maximum indicates the complex formation between two species in solution. However, there is no remarkable change in the shape of
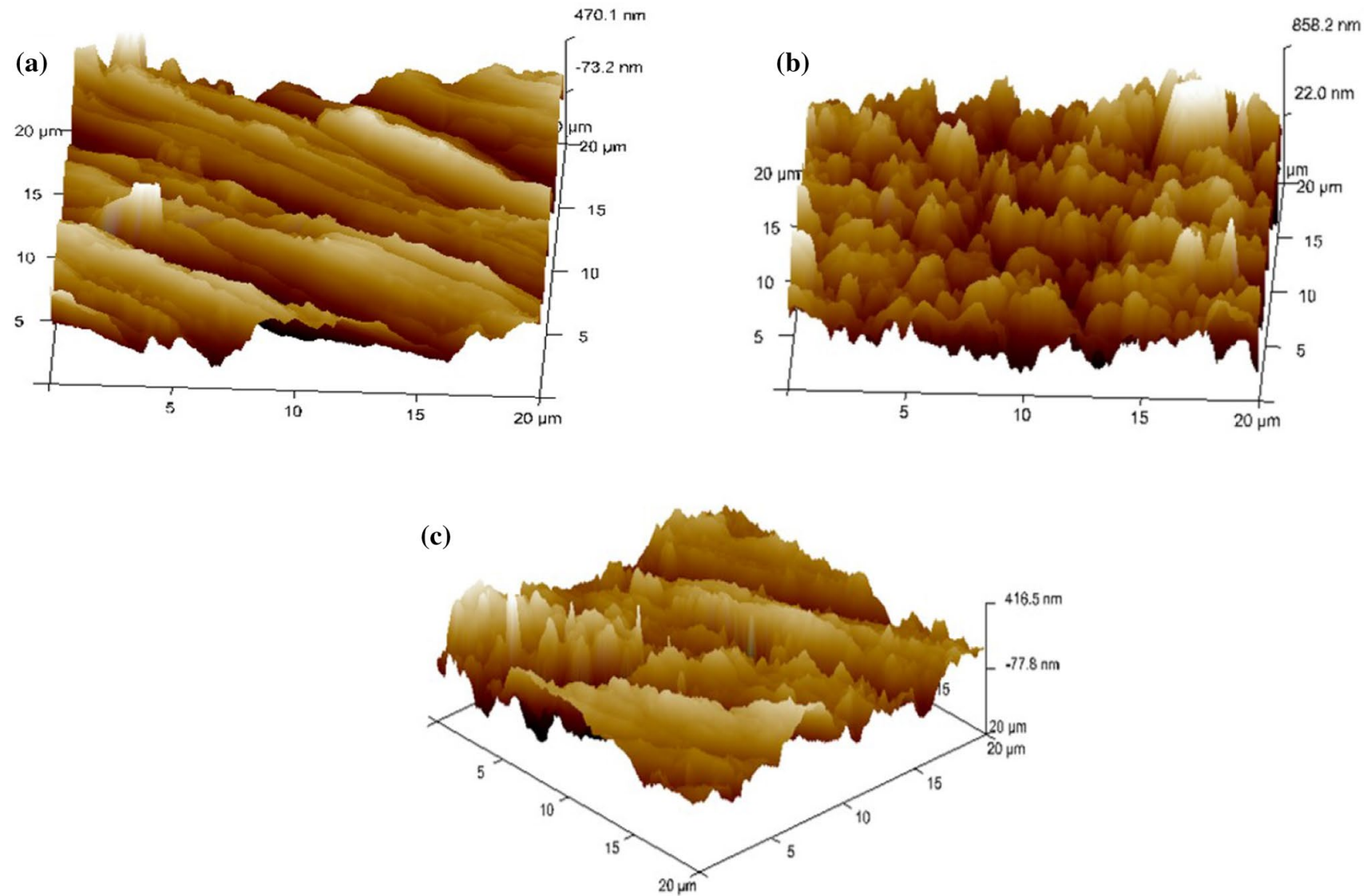

Fig. 5 AFM spectra of (a) freshly polished zinc (b) Zinc $+0.25 \mathrm{M} \mathrm{NH}_{2} \mathrm{SO}_{3} \mathrm{H}(\mathbf{c}) \mathrm{Zinc}+\mathrm{NH}_{2} \mathrm{SO}_{3} \mathrm{H}+0.05 \mathrm{gL}^{-1} \mathrm{GLY}$ 
the absorption spectra. This spectroscopic technique provide proof for the formation of complex between $\mathrm{Zn}^{2+}$ and GLY (Gadow and Motawea 2017).

\section{Mechanism of corrosion and inhibition process}

The chemical structure of the inhibitor, the charge on the molecule, the behaviour of the corrosive medium and the surface characteristics of the metal are the factors which influence the adsorption of the inhibitor onto the metal surface. Inhibitors adsorb on to the metal from aqueous solution, by blocking the active sites present on the metal which are susceptible to corrosion. GLY molecule has the presence of large number of oxygen atoms containing lone pair of electrons which help in strong adsorption onto the zinc surface by the formation of co-ordinate bond (Dahiya et al. 2017).

The interaction between zinc and the GLY predominantly obeyed chemisorption as suggested by the thermodynamic parameters. The presence of oxygen in the inhibitor molecule having lone pair of electrons has promoted chemical adsorption onto the metal surface. This process is accompanied by the replacement of water molecules adsorbed onto the metal surface. GLY molecule belongs to the category of biopolymers, it is obvious that the molecule is bigger in size and hence it is capable of covering both cathodic and anodic area due to Umbrella effect. Thus it acts as a mixed inhibitor. This explanation agrees very well with the observation of potentiodynamic polarisation method. To highlight the mechanism of adsorption and inhibition, a schematic representation is shown Fig. 7.

\section{Quantum chemical calculations}

The inhibition action of GLY on the metal zinc in $0.25 \mathrm{M}$ $\mathrm{NH}_{2} \mathrm{SO}_{3} \mathrm{H}$ medium was explained by quantum mechanical

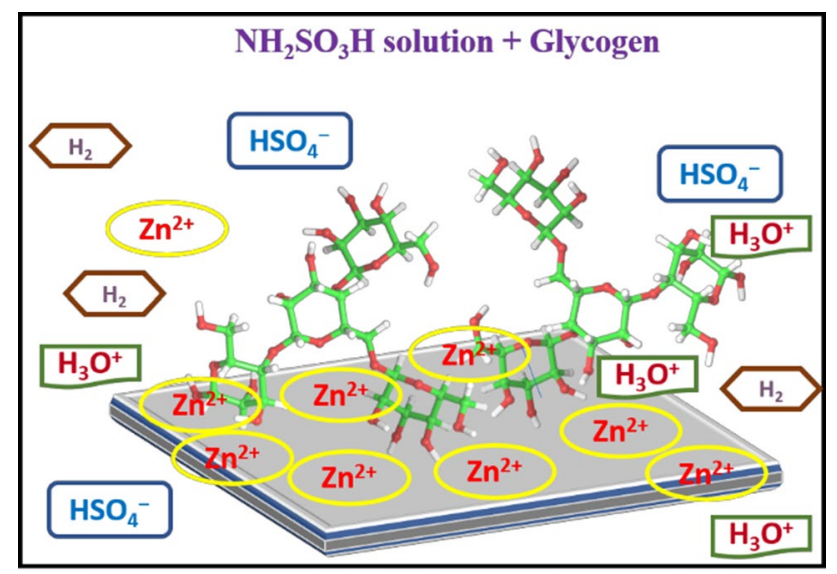

studies using DFT method. Corrosion inhibition ability of the molecule solely depends on the adsorption power and also the electron releasing ability of the molecule. DFT method enables the calculation of various chemical functional parameters like energy of HOMO, LUMO, energy gap $(\Delta E)$, dipole moment $(\mu)$ Mullikan charges etc.,

Optimised structure of GLY is shown in Fig. 8a. The optimized geometry of frontier molecular orbital of HOMO and LUMO are shown in the Fig. 8b, c. The distribution of electron density is localized both on HOMO and LUMO. This confirmed that the both the electron accepting and donating centres are present in GLY.

Various quantum mechanical parameters for the GLY is tabulated in the Table 3 and discussed in detail in the following section.

According to the frontier molecular orbital theory (FMO), the energy gap $\left(\Delta E=E_{\mathrm{LUMO}}-E_{\mathrm{HOMO}}\right)$ is related to the inhibition efficiency of inhibitor (Gupta et al. 2017). Adsorption of GLY onto the zinc surface can occur through donor acceptor interactions with the biopolymer that can donate electrons. Commonly, $E_{\text {Номо }}$ represents the electron donating ability of the inhibitor molecule. Any inhibitor characterized by higher value of $E_{\mathrm{HOMO}}$ is linked with higher electron donating ability. On the other hand, the highest occupied molecular frontier electron apportionment represents the region liable for electron giving. $E_{\text {LUMO }}$ represents the electron-accepting ability of the inhibitor molecule into its vacuous anti-bonding molecular orbital. The energy gap $(\Delta E=6.7295 \mathrm{eV})$ demonstrates the inherent electron donating ability and measures the interaction of the inhibitor molecule with the zinc surface.

It has been reported that low values of $\Delta E$ will provide good inhibition efficiency, because the energy for removing an electron from the last occupied orbital will be low (Arukalam 2014). The HOMO is concentrated in the zone to the oxygen (Fig. 8b), which is attributed to the presence of a lone pair of electrons in the oxygen atom of GLY. So, the preferred active sites for donating electrons in GLY are located in the regions around the oxygen atoms.

The dipole moment $(\mu)$ value of GLY is 12.56 Debye which is higher than the dipole moment of water $(1.88$ Debye), indicating that there is a strong dipole-dipole interaction between the inhibitor molecule and the zinc surface. This implies that the displacement of the water molecules from the metal surface is favourable and GLY gets chemically adsorbed onto the metal surface (Idir and Kellou-Kerkouche 2018).

Following Koopman's theorem, the molecular orbital energies of the FMO can be related to the ionization potential and electron affinity as per the Eqs. (7) and (8) (Geerlings et al. 2003; Obot et al. 2015; Chauhan et al. 2018).

Fig. 7 Representation of chemical adsorption of GLY over zinc 
Fig. 8 a Optimised structure of GLY (b) HOMO (c) LUMO

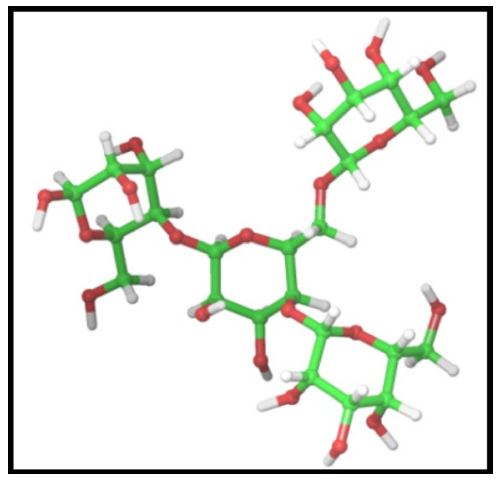

(a)

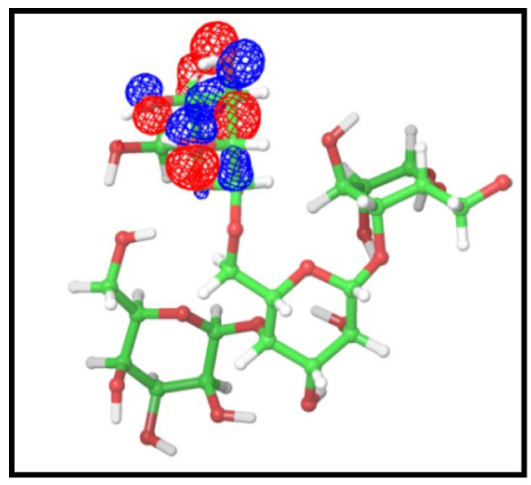

(b)

$\Delta \mathrm{E}=6.7295 \mathrm{eV}$

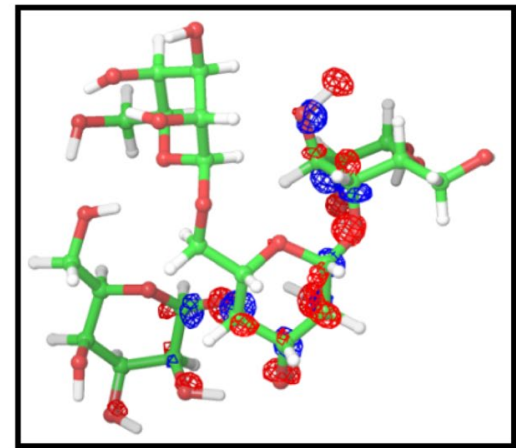

(c)
Table 3 Quantum chemical parameters of the neutral GLY

$-E_{\mathrm{HOMO}}=I$,

$-E_{\mathrm{LUMO}}=A$,

where $I$ and $A$ represent the ionization potential and the electron affinity, respectively. The electronegativity and hardness can be computed from the above parameters as per the Eqs. (9) and (10)

$\chi=\frac{1}{2}(I+A)$,

$\eta=\frac{1}{2}(I-A)=\frac{1}{\sigma}$,

where $\chi$ represents the absolute electronegativity, $\eta$ denotes the chemical hardness and $\sigma$ is the global softness which is the reciprocal of hardness. The electrophilicity index $(\omega)$ and its inverse, the nucleophilicity $(\varepsilon)$ can be calculated using Eq. (11)

$\omega=\frac{\chi^{2}}{4 \eta}=\frac{1}{\varepsilon}$.

Computed values of electronegativity $(\chi)$ and chemical hardness $(\eta)$ enables the evaluation of fraction of electron transferred $(\Delta N)$ (Geerlings et al. 2003; Chauhan et al. 2018; Obot et al. 2013) using the relation (12).

$\Delta N=\frac{\phi_{\mathrm{Zn}}-\chi_{\mathrm{inh}}}{2 \eta_{\mathrm{inh}}}$,

where $\phi_{\mathrm{Zn}}$ is the work function of the $\mathrm{Zn}$ which is equal to $4.31 \mathrm{eV}$. As per the reported literature (Obot et al. 2015) $\Delta N$ value less than 3.6 suggests the electron releasing ability of 


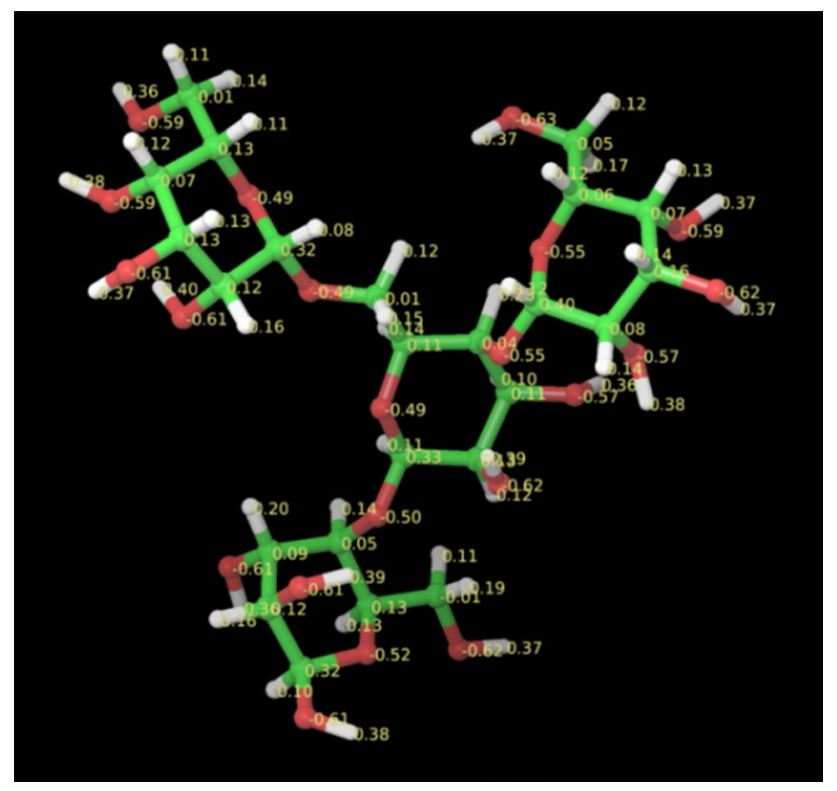

Fig. 9 Mullikan charge population

the inhibitor molecule. Calculated value of $\Delta N$ value for GLY is 0.145 , which clearly suggests its electron releasing ability thereby confirming the formation the physical barrier on the metal surface.

Further, the low value of the global softness $(\sigma)$ and high value of the global hardness $(\eta)$ also supported the strong interaction between the $\mathrm{Zn}$ metal and the inhibitor (Abd El Wanees and Seda 2019). The absolute electronegativity $(\chi)$ and global electrophilicity ( $\omega)$ of GLY were 3.334 and 0.8263 which indicated the stability and reactivity of inhibitor molecule.

Mullikan charge population for GLY is shown in Fig. 9. and the values are tabulated in the Table S5.

Mullikan charge density values provide useful information in locating high electron density region of the inhibitor molecule (Gao and Liang 2007; Hasanov et al. 2007). Higher the electron density on the heteroatom, stronger will be the coordinate bond between inhibitor and metal ( $\mathrm{Li}$ et al. 2007). Careful observation of Fig. 9 shows accumulation of excess of negative charges on the oxygen atom of $-\mathrm{OH}$ group. This facilitates the barrier between the metal and the corrosive and brings down the corrosion rate. The data of quantum calculations prove that the used inhibitor is characterized by more active adsorption sites that can easily adsorb on the metal surface to form a protective film.

\section{Conclusions}

1. A maximum inhibition efficiency of $71.2 \%$ was obtained for $0.05 \mathrm{~g} \mathrm{~L}^{-1}$ glycogen concentration at $323 \mathrm{~K}$.
2. Glycogen acted as a mixed inhibitor, underwent chemisorption and obeyed Langmuir adsorption isotherm.

3. Surface morphology studies by SEM, EDX, AFM confirmed the adsorption of glycogen.

4. Quantum chemical calculations are in good agreement with the experimental observations.

5. Glycogen emerged as an eco-friendly, nontoxic green inhibitor with environment and economic benefits.

Acknowledgements Ms. Mikitha Pais is grateful to MAHE, for the fellowship. Both the authors are thankful to Department of Chemistry, MIT MAHE for lab facilities, and Department of Mechanical Engineering, MIT MAHE, Department of Chemical Engineering, MIT, MAHE, Central Instrumentation Facilities MIT, MAHE for extending required facilities.

Funding Open access funding provided by Manipal Academy of Higher Education, Manipal.

Open Access This article is licensed under a Creative Commons Attribution 4.0 International License, which permits use, sharing, adaptation, distribution and reproduction in any medium or format, as long as you give appropriate credit to the original author(s) and the source, provide a link to the Creative Commons licence, and indicate if changes were made. The images or other third party material in this article are included in the article's Creative Commons licence, unless indicated otherwise in a credit line to the material. If material is not included in the article's Creative Commons licence and your intended use is not permitted by statutory regulation or exceeds the permitted use, you will need to obtain permission directly from the copyright holder. To view a copy of this licence, visit http://creativecommons.org/licenses/by/4.0/.

\section{References}

Abd El Wanees S, Seda SH (2019) Corrosion inhibition of zinc in aqueous acidic media using a novel synthesized Schiff basean experimental and theoretical study. J Dispers Sci Technol 40:1813-1826. https://doi.org/10.1080/01932691.2018.1544080

Abd El-Maksoud SA, Fouda AS (2005) Some pyridine derivatives as corrosion inhibitors for carbon steel in acidic medium. Mater Chem Phys 93:84-90. https://doi.org/10.1016/j.matchemphy s.2005.02.020

Abdel Hameed RS, AlShafey HI, Abu-Nawwas AH (2014) 2-(2, 6-Dichloranilino) phenyl acetic acid drugs as eco-friendly corrosion inhibitors for mild steel in $1 \mathrm{M} \mathrm{HCl}$. Int J Electrochem Sci 9:6006-6019

Abdel-Gaber AM (2007) Effect of immersion time and temperature on the inhibition of the acid corrosion of zinc by fenugreek seeds extract. Int J Appl Chem 3:161-174

Alsaleh K, Khalil KS (2014) Corrosion inhibition of zinc in hydrochloric acid solution using Ampicillin. Iraqi J Sci 55:295-303. https:// doi.org/10.22401/jnus.10.2.05

Ansari KR, Quraishi MA, Singh A et al (2016) Corrosion inhibition of $\mathrm{N} 80$ steel in $15 \% \mathrm{HCl}$ by pyrazolone derivatives: electrochemical, surface and quantum chemical studies. RSC Adv 6:24130-24141. https://doi.org/10.1039/c5ra25441h

Arukalam IO (2014) Durability and synergistic effects of KI on the acid corrosion inhibition of mild steel by hydroxypropyl 
methylcellulose. Carbohydr Polym 112:291-299. https://doi. org/10.1016/j.carbpol.2014.05.071

Bentiss F, Traisnel M, Lagrenee M (2000) The substituted 1,3,4-oxadiazoles: a new class of corrosion inhibitors of mild steel in acidic media. Corros Sci 42:127-146. https://doi.org/10.1016/S0010 -938X(99)00049-9

Bentiss F, Traisnel M, Lagrenee M (2001) Infuence of 2,5-bis(4dimethylaminophenyl)-1,3,4-thiadiazole on corrosion inhibition of mild steel in acidic media. J Appl Electrochem 31:41-48

Bouklah M, Hammouti B, Lagrenée M, Bentiss F (2006) Thermodynamic properties of 2,5-bis(4-methoxyphenyl)-1,3,4-oxadiazole as a corrosion inhibitor for mild steel in normal sulfuric acid medium. Corros Sci 48:2831-2842. https://doi.org/10.1016/j. corsci.2005.08.019

Charitha BP, Rao P (2017a) Carbohydrate biopolymer for corrosion control of $6061 \mathrm{Al}$-alloy and 6061Aluminum-15\%(v) SiC(P) composite-green approach. Carbohydr Polym 168:337-345. https:// doi.org/10.1016/j.carbpol.2017.03.098

Charitha BP, Rao P (2017b) An ecofriendly approach for corrosion control of $6061 \mathrm{Al}-15 \%$ (v) $\mathrm{SiC}(\mathrm{P})$ composite and its base alloy. Chinese J Chem Eng 25:363-372. https://doi.org/10.1016/j.cjche .2016 .08 .007

Charitha BP, Rao P (2018a) Environmentally benign green inhibitor to attenuate acid corrosion of 6061 Aluminum-15\%(v) $\mathrm{SiC}(\mathrm{P})$ composite. J Ind Eng Chem 58:357-368. https://doi.org/10.1016/j. jiec.2017.09.049

Charitha BP, Rao P (2018b) Pullulan as a potent green inhibitor for corrosion mitigation of aluminum composite: electrochemical and surface studies. Int J Biol Macromol 112:461-472. https://doi. org/10.1016/j.ijbiomac.2018.01.218

Chauhan DS, Ansari KR, Sorour AA et al (2018) Thiosemicarbazide and thiocarbohydrazide functionalized chitosan as ecofriendly corrosion inhibitors for carbon steel in hydrochloric acid solution. Int J Biol Macromol 107:1747-1757. https://doi.org/10.1016/j. ijbiomac.2017.10.050

Dahiya S, Kumar P, Lata S et al (2017) An exhaustive study of a coupling reagent (1-(3-dimethylaminopropyl) 3-ethylcarbodiimide hydrochloride) as corrosion inhibitor for steel. Indian J Chem Technol 24:327-335

El-Deeb MM, Ads EN, Humaidi JR (2018) Evaluation of the modified extracted lignin from wheat straw as corrosion inhibitors for aluminum in Alkaline solution. Int J Electrochem Sci 13:4123-4138. https://doi.org/10.20964/2018.05.49

El-Sherbini EEF, Wahaab SMA, Deyab M (2005) Ethoxylated fatty acids as inhibitors for the corrosion of zinc in acid media. Mater Chem Phys 89:183-191. https://doi.org/10.1016/j.matchemphy s.2003.09.055

Fouda AS, Rashwan S, Emam A, El-Morsy FE (2018) Corrosion inhibition of zinc in acid medium using some novel organic compounds. Int J Electrochem Sci 13:3719-3744. https://doi. org/10.20964/2018.04.23

Gadow HS, Motawea MM (2017) Investigation of the corrosion inhibition of carbon steel in hydrochloric acid solution by using ginger roots extract. RSC Adv 7:24576-24588. https://doi.org/10.1039/ c6ra28636d

Gao G, Liang C (2007) Electrochemical and DFT studies of $\beta$-aminoalcohols as corrosion inhibitors for brass. Electrochim Acta 52:4554-4559. https://doi.org/10.1016/j.electacta.2006.12.058

Geerlings P, De Proft F, Langenaeker W (2003) Conceptual density functional theory. Chem Rev 103:1793-1873. https://doi. org/10.1021/cr990029p

Gupta NK, Verma C, Salghi R et al (2017) New phosphonate based corrosion inhibitors for mild steel in hydrochloric acid useful for industrial pickling processes: experimental and theoretical approach. New J Chem 41:13114-13129. https://doi.org/10.1039/ c7nj01431g
Hasanov R, Sadikoğlu M, Bilgiç S (2007) Electrochemical and quantum chemical studies of some Schiff bases on the corrosion of steel in $\mathrm{H}_{2} \mathrm{SO}_{4}$ solution. Appl Surf Sci 253:3913-3921. https:// doi.org/10.1016/j.apsusc.2006.08.025

Hermas AA, Morad MS (2008) A comparative study on the corrosion behaviour of 304 austenitic stainless steel in sulfamic and sulfuric acid solutions. Corros Sci 50:2710-2717. https://doi. org/10.1016/j.corsci.2008.06.029

Hosseini M, Mertens SFL, Arshadi MR (2003) Synergism and antagonism in mild steel corrosion inhibition by sodium dodecylbenzenesulphonate and hexamethylenetetramine. Corros Sci 45:14731489. https://doi.org/10.1016/S0010-938X(02)00246-9

Hu Q, Qiu Y, Zhang G, Guo X (2015) Capsella bursa-pastoris extract as an eco-friendly inhibitor on the corrosion of Q235 carbon steels in $1 \mathrm{~mol} \mathrm{~L}^{-1}$ hydrochloric acid. Chinese J Chem Eng 23:1408-1415. https://doi.org/10.1016/j.cjche.2015.05.002

Idir B, Kellou-Kerkouche F (2018) Experimental and theoretical studies on corrosion inhibition performance of phenanthroline for cast iron in acid solution. J Electrochem Sci Technol 9:260 275. https://doi.org/10.33961/jecst.2018.9.4.260

Karthik G, Sundaravadivelu M (2016) Studies on the inhibition of mild steel corrosion in hydrochloric acid solution by atenolol drug. Egypt J Petrol 25:183-191. https://doi.org/10.1016/j. ejpe.2015.04.003

Karthikeyan S (2016) Drugs/antibiotics as potential corrosion inhibitors for metals - a review. Int J ChemTech Res 9:251-259

Khadiri A, Saddik R, Bekkouche K et al (2016) Gravimetric, electrochemical and quantum chemical studies of some pyridazine derivatives as corrosion inhibitors for mild steel in $1 \mathrm{M} \mathrm{HCl}$ solution. J Taiwan Inst Chem Eng 58:552-564. https://doi. org/10.1016/j.jtice.2015.06.031

Khaled KF (2008) Guanidine derivative as a new corrosion inhibitor for copper in 3\% NaCl solution. Mater Chem Phys 112:104-111. https://doi.org/10.1016/j.matchemphys.2008.05.052

Krishnaveni K, Sampath K, Ravichandran J, Jayabalakrishnan C (2015) N-methyl-2-(2-nitrobenzylidene) hydrazine carbothioamide - a new corrosion inhibitor for mild steel in $1 \mathrm{~mol} \mathrm{~L}^{-1}$ hydrochloric acid. Chinese J Chem Eng 23:1916-1922. https:// doi.org/10.1016/j.cjche.2015.08.004

Kumar S, Ladha DG, Jha PC, Shah NK (2013) Theoretical study of chloro- $N$-(4-methoxybenzylidene)aniline derivatives as corrosion inhibitors for zinc in hydrochloric acid. Int J Corros 2013. https://doi.org/10.1155/2013/819643

Li W, He Q, Pei C, Hou B (2007) Experimental and theoretical investigation of the adsorption behaviour of new triazole derivatives as inhibitors for mild steel corrosion in acid media. Electrochim Acta 52:6386-6394. https://doi.org/10.1016/j.elect acta.2007.04.077

Li WH, He Q, Zhang ST et al (2008) Some new triazole derivatives as inhibitors for mild steel corrosion in acidic medium. J Appl Electrochem 38:289-295. https://doi.org/10.1007/s10800-007-9437-7

Machnikova E, Whitmire KH, Hackerman N (2008) Corrosion inhibition of carbon steel in hydrochloric acid by furan derivatives. Electrochim Acta 53:6024-6032. https://doi.org/10.1016/j.elect acta.2008.03.021

Mahida MB, Chaudhari HG (2012) Aliphatic amines as corrosion inhibitors for zinc in hydrochloric acid. Der Pharma Chem 4:2305-2312

Martinez S, Metikoš-Huković M (2003) A nonlinear kinetic model introduced for the corrosion inhibitive properties of some organic inhibitors. J Appl Electrochem 33:1137-1142. https://doi. org/10.1023/B:JACH.0000003851.82985.5e

Mishra A, Verma C, Lgaz H et al (2018) Synthesis, characterization and corrosion inhibition studies of $\mathrm{N}$-phenyl-benzamides on the acidic corrosion of mild steel: experimental and computational 
studies. J Mol Liq 251:317-332. https://doi.org/10.1016/j.molli q.2017.12.011

Morad MS (2008) Corrosion inhibition of mild steel in sulfamic acid solution by S-containing amino acids. J Appl Electrochem 38:1509-1518. https://doi.org/10.1007/s10800-008-9595-2

Nwosu FO, Muzakir MM (2016) Thermodynamic and adsorption studies of corrosion inhibition of mild steel using lignin from siam weed (chromolaena odorata) in acid medium. J Mater Environ Sci 7:1663-1673

Obot IB, Ebenso EE, Kabanda MM (2013) Metronidazole as environmentally safe corrosion inhibitor for mild steel in $0.5 \mathrm{M} \mathrm{HCl}$ : experimental and theoretical investigation. J Environ Chem Eng 1:431-439. https://doi.org/10.1016/j.jece.2013.06.007

Obot IB, Macdonald DD, Gasem ZM (2015) Density functional theory (DFT) as a powerful tool for designing new organic corrosion inhibitors: part 1: an overview. Corros Sci 99:1-30. https://doi. org/10.1016/j.corsci.2015.01.037

Oguzie EE, Njoku VO, Enenebeaku CK et al (2008) Effect of hexamethylpararosaniline chloride (crystal violet) on mild steel corrosion in acidic media. Corros Sci 50:3480-3486. https://doi. org/10.1016/j.corsci.2008.09.017

Okafor PC, Zheng Y (2009) Synergistic inhibition behaviour of methylbenzyl quaternary imidazoline derivative and iodide ions on mild steel in $\mathrm{H}_{2} \mathrm{SO}_{4}$ solutions. Corros Sci 51:850-859. https://doi. org/10.1016/j.corsci.2009.01.027

Peng Y, Song G (2002) Combined microwave and ultrasound assisted Williamson ether synthesis in the absence of phase-transfer catalysts. Green Chem 4:349-351. https://doi.org/10.1039/b201543a

Prakashaiah BG, Vinaya Kumara D, Anup Pandith A et al (2018) Corrosion inhibition of 2024-T3 aluminum alloy in 3.5\% $\mathrm{NaCl}$ by thiosemicarbazone derivatives. Corros Sci 136:326-338. https:// doi.org/10.1016/j.corsci.2018.03.021

Quraishi MA, Rawat J, Ajmal M (2000) Dithiobiurets: a novel class of acid corrosion inhibitors for mild steel. J Appl Electrochem 30:745-751. https://doi.org/10.1023/A:1004099412974

Raja PB, Fadaeinasab M, Qureshi AK et al (2013) Evaluation of green corrosion inhibition by alkaloid extracts of Ochrosia oppositifolia and isoreserpiline against mild steel in $1 \mathrm{M} \mathrm{HCl}$ medium. Ind Eng Chem Res 52:10582-10593. https://doi.org/10.1021/ie401387s

Sahin M, Bilgic S, Yilmaz H (2002) The inhibition effects of some cyclic nitrogen compounds on the corrosion of the steel in $\mathrm{NaCl}$ mediums. Appl Surf Sci 195:1-7. https://doi.org/10.1016/S0169 -4332(01)00783-8

Singh P, Ebenso EE, Olasunkanmi LO et al (2016) Electrochemical, theoretical, and surface morphological studies of corrosion inhibition effect of green naphthyridine derivatives on mild steel in hydrochloric acid. J Phys Chem C 120:3408-3419. https://doi. org/10.1021/acs.jpcc.5b11901

Vashi RT, Desai K (2012) Hexamine as corrosion inhibitor for zinc in hydrochloric acid. Der Pharma Chem 4:2117-2123

Verma C, Quraishi MA (2016) 2-Amino-3-methyl-3-(4-nitrophenyl)5-(phenylthio)- $3 \mathrm{H}$-pyrrole-4-carbonitrile as effective corrosion inhibitor for mild steel in $1 \mathrm{M} \mathrm{HCl}$ : thermodynamical, electrochemical, surface and theoretical calculation. Ain Shams Eng J 7:1-9. https://doi.org/10.1016/j.asej.2015.11.017

Verma C, Olasunkanmi LO, Ebenso EE et al (2016) Adsorption behavior of glucosamine-based, pyrimidine-fused heterocycles as green corrosion inhibitors for mild steel: experimental and theoretical studies. J Phys Chem C 120:11598-11611. https:// doi.org/10.1021/acs.jpcc.6b04429

Verma C, Quraishi MA, Kluza K et al (2017) Corrosion inhibition of mild steel in $1 \mathrm{M} \mathrm{HCl}$ by D-glucose derivatives of dihydropyrido [2,3-d:6,5- $\left.d^{\prime}\right]$ dipyrimidine-2, 4, 6, 8(1H,3H, 5H,7H)-tetraone. Sci Rep 7:44432. https://doi.org/10.1038/srep44432

Zhang XG (1996) Corrosion and electrochemistry of zinc, 1st edn. Springer Science Business Media, Plenum Press, New York

Zulfareen N, Venugopal T, Kannan K (2018) Experimental and theoretical studies on the corrosion inhibition of brass in hydrochloric acid by $N$-(4-((4-benzhydryl piperazin-1-yl) methyl carbamoyl) phenyl) furan-2-carboxamide. Int J Corros 2018:1-18

Publisher's Note Springer Nature remains neutral with regard to jurisdictional claims in published maps and institutional affiliations. 